\title{
Feeding Performance in Preterm Infants and Full Term Infants at 40 Weeks Postmenstrual Age
}

\author{
Gupta $\mathbf{G}^{1}$, KVK Vijay ${ }^{2}$, Anitha $\mathrm{R}^{3}$, Ninan $\mathrm{B}^{4}$
}

${ }^{1}$ Gunjan Gupta, MASLP, Audiologist and Speech Language Pathologist, SpHear Speech and Hearing Clinic, Noida, UP, India. ${ }^{2}$ Vijay Kumar, KV, MASLP, Senior Lecturer, Department of Speech, Language and Hearing Sciences, ${ }^{3}$ Anitha. R, M.Sc (Sp \& Hg) Senior Assistant Professor, Department of Speech, Language and Hearing Sciences, ${ }^{4} \mathrm{Dr}$. Binu Ninan, MD, DNB, DCH, MRCP, Professor and Head, Department of Neonatology, Sri Ramachandra University, Chennai, India.

\section{Address for correspondence:}

Vijay Kumar, KV, Senior Lecturer,

Department of Speech, Language and Hearing

Sciences,

Sri Ramachandra University,

Porur, Chennai-600 116.

Tel No; +919710920103

E-mail:vijaykumarkv@yahoo.in

\section{Acknowledgements: None}

Funding: Nil

Conflict of Interest: This study was done as a part of Master dissertation for the degree of Masters in Audiology and Speech Language Pathology at Sri Ramachandra University. The authors do not have any conflict of interest in real or perceived including study design, the collection, analysis, and interpretation of data, writing of the report and the decision to submit the paper for publication.

Permission from IRB: This study adhered to the guidelines of Indian Council of Medical Research (ICMR) and was approved by the Internal Ethics committee and the Publication oversite committee (POC) of the University.

Ethical dilemmas faced during study: No

\section{How to cite}

Gupta G, KVK Vijay, Anitha R, Ninan B. Feeding Performance in Preterm Infants and Full Term Infants at 40 Weeks Postmenstrual Age. J Nepal Paediatr Soc 2016;36(2):136-140.

doi: http://dx.doi.org/10.3126/jnps.v36i2.14621

This work is licensed under a Creative Commons Attribution 3.0 License.

\begin{abstract}
Introduction: Feeding problems are commonly reported among preterm infants. As premature infants are born before adequate maturation, inadequate feeding capabilities are common among preterm infants. Feeding is an innate behaviour in a new born. Swallowing is evident in a foetus by $16^{\text {th }}$ week of gestation (Tuchman, 1994). By $40^{\text {th }}$ week of gestation, neural processes are expected to mature completely. Feeding is an innate behaviour in a new born. Swallowing is evident in a foetus by $16^{\text {th }}$ week of gestation. By $40^{\text {th }}$ week of gestation, neural processes are expected to mature completely. Since the premature infants are born before adequate maturation of the systems, it is not unusual for them to have inadequate feeding capabilities. Material and Methods: This study aimed to compare feeding performance in preterm (between 30 and 34 weeks GA) and full term infants at 40 weeks Post menstrual age. Seventy infants and their mothers served as participants. A close ended questionnaire documented the oral reflexes, oro-motor skills, oro-sensory skills and feeding history in infants. Results: Results were tabulated under feeding history, (viz; history of use of nasogastric feeding, duration of feeding, episodes of coughing/ choking and vomiting, fussing during feeding, noisy breathing) and oral skills. Significant difference in feeding behaviour was observed between the term and preterm infants at 40 weeks post menstrual age. Conclusion: Hence the need for Speech Language Pathologist to evaluate feeding behaviour at 40 weeks post menstrual age becomes necessary.
\end{abstract}

Key words: Feeding, Oral skills, Term infants, Preterm infants

\section{Introduction}

Eeeding is an innate behaviour in a new born. Swallowing is evident in a foetus by $16^{\text {th }}$ week of gestation 1 . By $40^{\text {th }}$ week of gestation, neural processes are expected to mature completely ${ }^{2}$. The frequency of sucking and swallowing patterns increases in preterm and full term infants during the final weeks of foetal life ${ }^{3}$. Parallel to neurological development, the primitive suck and swallow reflexes transform to a mature, voluntary and integrated function. Since the premature infants 
are born before adequate maturation of the systems, it is not unusual for them to have inadequate feeding capabilities.

Successful oral feeding requires normal oral reflexes, orosensory and oromotor skills ${ }^{4}$. Feeding problems are reported in preterm infants, particularly those who are born before 30 weeks or with associated medical co-morbidities ${ }^{5}$. The common signs/symptoms are altered oral reflexes and oral sensitivity, oromotor dysfunction, use of nasogastric (NG) tube, increased duration of feeding, coughing/choking, vomiting, fussing during feeding, and noisy breathing ${ }^{6}$. This feeding disorder in a neonate impedes the mother child interaction and hinders the early language development and neurodevelopment ${ }^{7}$.

Exploring feeding performance at the maturational age of 40 weeks postmenstrual age (PMA) would yield better reflection of the integrity of the neurological system. Studies till date have been scant for preterm infants between 30- 34 weeks of Gestational Age (GA) and their feeding outcome at 40 weeks PMA. An evaluation of feeding at 40 weeks PMA would be beneficial in order to identify early feeding problems in preterm infants and would thus help in early intervention.

The study aims to compare the feeding performance in preterm infants (30 - 34 weeks GA) and full term infants at 40 weeks PMA.

\section{Material and Methods}

Seventy (35 preterm and 35 full term) infants and their mothers' participated in this study. This study was carried out over a period of 3 months on the infants at $40^{\text {th }}$ week PMA. The questionnaire was prepared based on available literature and the content validity was obtained.

The infants were assessed by a speech language pathologist during the feeding and were assessed for oral reflexes (rooting, gag, suckling, phasic bite, mouth opening), oromotor skills (suck-swallow co-ordination, loss of liquids/ spillage of milk from mouth, lip seal, non-nutritive sucking, tongue movements and laryngeal elevation) and oral sensitivity (hypersensitivity and hyposensitivity).

A close ended questionnaire was prepared to document the oral reflexes, oromotor skills, orosensory skills and feeding history. Using this questionnaire, the mothers were interviewed on the feeding history of the infants. The questions in the feeding history included: mode of feeding, use of nasogastric tube, duration of feeding, episodes of choking/coughing, vomiting, fussing during feeding and noisy breathing. Hospital record of each infant was referred for detailed reports of the medical and feeding history. The responses were subjected to Percentage analysis and Pearson ChiSquare $\left(X^{2}\right)$ analysis.

\section{Results}

Feeding history: History of use of NG feeding

Table 1: Percentage analysis, chi-square value $\left(x^{2}\right)$ and significance $(p)$ value for use of NG tube in preterm and full term infant groups

\begin{tabular}{cccccc}
\hline Feeding History & Response & Preterm infants (\%) & Full term infants (\%) & $\mathbf{X}^{2}$ & $p$-value \\
\hline \multirow{3}{*}{ Use of NG tube } & Not Required & 2.9 & 100 & & \multirow{2}{*}{66.111} \\
\cline { 2 - 5 } & $0-6$ days & 28.6 & 0 & $<0.01^{\text {** }}$ \\
\cline { 2 - 5 } & $>6$ days & 68.6 & 0 & \\
\hline
\end{tabular}

Note: ${ }^{* *}$ significant at $p \leq 0.01$

Feeding history: Current modes of feeding

Table 2: Percentage analysis, chi-square value $\left(x^{2}\right)$ and significance $(p)$ value for current mode of feeding in preterm and full term infant groups

\begin{tabular}{cccccc}
\hline Feeding History & Response & Preterm infants (\%) & Full term infants (\%) & $\mathbf{X}^{2}$ & $p$-value \\
\hline \multirow{3}{*}{ Modes of feeding } & DBF & 34.3 & 97.1 & & \\
\cline { 2 - 5 } & Paladai & 5.7 & 0 & 30.704 & $<0.01^{* *}$ \\
\cline { 2 - 5 } & Both & 60 & 2.9 & & \\
\hline
\end{tabular}

Note: ** significant at $p \leq 0.01$ 
Feeding in Preterm and Term Neonates

Feeding history: Duration of feeding

Table 3: Percentage analysis, chi-square value $\left(X^{2}\right)$ and significance $(p)$ value for duration of feeding in preterm and full term infant groups

\begin{tabular}{|c|c|c|c|c|c|}
\hline Feeding History & Response & Preterm infants (\%) & Full term infants (\%) & $\mathrm{X}^{2}$ & $p$ value \\
\hline \multirow{3}{*}{ Duration of feeding } & $5-10 \min$ & 8.6 & 2.9 & \multirow{3}{*}{9.556} & \multirow{3}{*}{$<0.01^{* *}$} \\
\hline & $10-15 \min$ & 51.4 & 85.7 & & \\
\hline & $>15 \min$ & 40 & 11.4 & & \\
\hline
\end{tabular}

Note: ** significant at $p \leq 0.01$

Feeding history: Episodes of coughing/ choking

Table 4: Percentage analysis, chi-square value $\left(x^{2}\right)$ and significance $(p)$ value for episodes of coughing/choking in preterm and full term infant groups

\begin{tabular}{cccccc}
\hline \multirow{2}{*}{ Feeding History } & Response & Preterm infants (\%) & Full term infants (\%) & $X^{2}$ & $p$ value \\
\hline \multirow{2}{*}{ Coughing } & Present & 2.9 & 0 & \multirow{2}{*}{7.778} & $0.02^{*}$ \\
\cline { 2 - 5 } & Sometimes & 17.1 & 0 & \\
\hline
\end{tabular}

Note: *significant at $p \leq 0.05$

Feeding history: Episodes of vomiting

Table 5: Percentage analysis, chi-square value $\left(X^{2}\right)$ and significance $(p)$ value for episodes of vomiting during feeding in preterm and full term infant groups

\begin{tabular}{|c|c|c|c|c|c|}
\hline Feeding History & Response & Preterm infants (\%) & Full term infants (\%) & $x^{2}$ & $p$-value \\
\hline \multirow{2}{*}{ Vomiting } & Present & 2.9 & 0 & \multirow{2}{*}{9.032} & \multirow{2}{*}{$0.011^{*}$} \\
\hline & Sometimes & 20 & 0 & & \\
\hline
\end{tabular}

Note: ${ }^{*}$ significant at $p \leq 0.05$

Feeding history: Fussing during feeding

Table 6: Percentage analysis, chi-square value $\left(x^{2}\right)$ and significance $(p)$ for occurrence of fussing during feeding in preterm and full term infant groups

\begin{tabular}{|c|c|c|c|c|c|}
\hline Feeding History & Response & Preterm infants (\%) & Full term infants (\%) & $x^{2}$ & $p$-value \\
\hline \multirow{2}{*}{ Fussing during feeding } & Present & 0 & 0 & \multirow{2}{*}{1.014} & \multirow{2}{*}{0.314} \\
\hline & Sometimes & 2.9 & 0 & & \\
\hline
\end{tabular}

Feeding history: Noisy breathing

Table 7: Percentage analysis, chi-square value $\left(x^{2}\right)$ and significance $(p)$ value for presence of noisy breathing during feeding in preterm and full term infant groups

\begin{tabular}{|c|c|c|c|c|c|}
\hline Feeding History & Response & Preterm infants (\%) & Full term infants (\%) & $x^{2}$ & $p$-value \\
\hline \multirow{2}{*}{ Noisy breathing } & Present & 2.9 & 0 & \multirow{2}{*}{4.242} & \multirow{2}{*}{$0.12^{*}$} \\
\hline & Sometimes & 8.6 & 0 & & \\
\hline
\end{tabular}

Note: * significant at $p \leq 0.05$

\section{Feeding history: Oral Skills}

Reflexes: Oral reflexes were present for $100 \%$ of preterm and full term infants. Oromotor skills which are pre-requisite (adequate lip seal, no liquid loss/ spillage, adequate tongue movement, non nutritive sucking and laryngeal elevation) was adequate for both preterm and full term infants. However, poor suck-swallow sequence was observed in $2.9 \%$ of the preterm infants. Among preterm infants $2.9 \%$ of them displayed hypersensitive behaviour. No overreactions were exhibited in any of the full term infants. This difference was not statistically significant $(p=0.314)$ between preterm and full term infants. 
Table 8: Percentage analysis, chi-square value $\left(x^{2}\right)$ and significance $(p)$ value for oro-motor skills present in preterm and full term infant groups

\begin{tabular}{lccccc}
\hline Oro-motor skills & Response & Preterm infants (\%) & Full term infants (\%) & $\mathbf{X}^{2}$ & $p$ value \\
\hline Lip seal & Present & 100 & 100 & - & - \\
\hline Loss of liquid & Absent & 100 & 100 & - & - \\
\hline Tongue movements & Present & 100 & 100 & - & - \\
\hline Non-nutritive sucking & Present & 100 & 100 & - & - \\
\hline Suck-swallow respiratory sequence & Present & 97.1 & 100 & 1.104 & 0.314 \\
\hline Laryngeal elevation during swallowing & Present & 100 & 100 & - & - \\
\hline
\end{tabular}

\section{Discussion}

This study aimed at comparing feeding performance of preterm infants (between 30 and 34 weeks GA) and age matched full term infants at 40 weeks Postmenstrual Age (PMA). The discussion for the results is as follows.

\section{Feeding history:}

i. History of use of NG feeding: Results revealed that $97.1 \%$ of preterm infants required feeding through nasogastric tube, with $68.6 \%$ of preterm infants requiring more than 6 days of NG tube feeding, whereas none of the full term infant required feeding through NG tube. Literature explains nasogastric tube as a general mode for nutrition intake in infants and young children exhibiting feeding problems ${ }^{8}$. Use of NG tube may have its own disadvantages. Tube inserted is a temporary device which is used to increase intake of food. This intrusive procedure, if continued for long, might be uncomfortable for the infant ${ }^{8}$.

ii. Current feeding mode: At the time of assessment (40 weeks PMA), $60 \%$ of preterm infants required both paladai and direct breastfeeding (DBF) for nutrition, while $34.3 \%$ were on mere DBF. The response of full term infants was unlike preterm infants, with $97.1 \%$ of them being fed by DBF. Of the full term group, $2.9 \%$ infants required supplementation of paladai with DBF. Newborns are born with an inborn capability to breastfeed ${ }^{9}$. The tube feeding to oral feeding is successful for the preterm infants who demonstrate strong reflexive behaviour and oro-motor functioning ${ }^{10}$.

iii. Duration of feeding: It was observed that $40 \%$ of preterm infants required more than 15 minutes to complete feeding as compared to $11.4 \%$ full term infants who required more than 15 minutes. This duration included time to rest, cough, or burp. Prolonged feeding times may relate to oral sensorimotor problems, airway issues and risks for aspiration, and poor parent-child interaction or behavioural based problems ${ }^{11}$. The preterm infants also feed more slowly than full-term infants ${ }^{12}$.

iv. Episodes of coughing/choking: Literature describes cough as a protective reflex involved in clearance of material in the airway. Choking and gagging on feedings are similar symptoms suggesting airway threats. Coughing and choking may present with aspiration, usually during feeding, and may be indicative of compromised airway protective reflexes ${ }^{13}$.

\section{Episodes of vomiting}

Vomiting may be indicative of esophageal disorders. Vomiting may occur when esophageal dysmotility prevents the appropriate caudal movement of ingested material resulting in material's retrograde movement ${ }^{13}$. It was found that $22.9 \%$ of preterm infants reported with complaint of vomiting, while none of the full term infant reported of vomiting.

\section{Fussing during feeding}

During the developmental phase of feeding, behaviors such as avoidance and food refusals can be observed in infants who receive negative experiences such as use of nasogastric tube during early feeding ${ }^{14}$.

\section{Noisy breathing}

Presence of noisy breathing may be a sign of respiratory distress. In the preterm group, mothers of $11.5 \%$ infants reported of noisy breathing during feeding. Among the full term group, none of the mothers reported of infants having noisy breathing. Breathing related problems are seen to induce noisy breathing and crying behaviors in preterm infants. Airway disturbances can be held responsible for feeding problems. It is mandatory to compare respiration of an infant during rest and feeding ${ }^{15}$. 


\section{Conclusion}

Preterm infants may not display issues in exhibiting oral reflexes, oromotor skills and oral sensitivity at 40 weeks PMA. They are observed to stay longer in Neonatal Intensive Care Unit (NICU) for extensive

\section{References}

1. Tuchman DN. Physiology of the swallowing apparatus. In: Tuchman DN, Walter RS, editors. Disorders of Feeding and Swallowing in Infants and Children, Pathophysiology, Diagnosis and Treatment. California, CA: Singular Publishing group; pp. 1-26.

2. Linderkamp O, Janus L, Linder R, Skoruppa, DB. Time table of normal foetal brain development. Int $J$ Prenatal Perinatal Psychol Med 2009;21(1/2):4-16.

3. Costa SP, Engel-Hoek L, Bos AF. Sucking and swallowing in infants and diagnostic tools. J Perinatol 2008;28:247-57

4. Pickler RH, Best A, Crosson D. The effect of feeding experience on clinical outcomes in preterm infants. $J$ Perinatol 2009;29:124-29.

5. Gewolb IH, Bosma, JF, Reynolds, EW Vice, FL. Integration of suck and swallow rhythms during feeding in preterm infants with and without bronchopulmonary dysplasia. Dev Med Child Neurol 2003;45(5):344-48.

6. Byars KC, Burklow KA., Ferguson K, O'Flaherty T, Santoro K, Kaul A. A multicomponent behavioral program for oral aversion in children dependent on gastrostomy feedings. J Pediatr Gastroenterol Nutr 2003;37:473-80.

7. Adams-Chapman I. Neurodevelopmental outcome of the late preterm infant. J Perinatol 2006;3:947-64.

8. Morris SE. Development of oro-motor skills in the neurologically impaired child receiving non-oral feedings. Dysphagia 1989;3:135-54.

9. Bergman N. Breastfeeding and Perinatal Neuroscience. In: Genna CW, editors. Supporting sucking skills in breastfeeding infants [Internet]. Burlington, Massachusetts: Jones \& Bartlett learning; use of NG tube. Preterm infants may have issues in direct breastfeeding, vomiting, coughing, fussing and swallowing-breathing coordination even after discharge from the hospital. The result mandates an assessment of feeding performance in preterm infants at 40 weeks of post menstrual age.
2013 [cited on 2014 May 13] Chapter 2. Available from: http://books.google.co.in/books?id=Z9Xw3pk z1YC\&pg=PA43\&dq=supporting+sucking+in+breas tfeeding+infants+chapter $+2 \& \mathrm{hl}=$ en\&ei $=1 \mathrm{bKOTcqqC}$ YPluAP2pKysDQ\&sa=X\&oi=book_result\&ct=result \& resnum $=1 \& v e d=0 C D c Q 6 A E w A A \# v=$ onepage $\& q=$ supporting $\% 20$ sucking $\% 20$ in $\% 20$ breastfeeding $\% 20$ infants $\% 20$ chapter\%202\&f=false

10. Bauer MA, Prade LS, Leske-Soares M, Haëffner LSB, Weinmann ARM. The oral motor capacity and feeding performance of preterm newborns at the time of transition to oral feeding. Braz J Med Biol Res 2008;41(10):904-7.

11. Arvedson JC. Swallowing and Feeding in infants and young children. GI motility online [Internet]. 2006 May [cited 2013 May 13]; doi:10.1038/gimo17.

12. Jain L, Sivieri E, Abbasi S, Bhutani VK. Energetics and mechanics of nutritive sucking in the preterm and term neonate. J Pediatr 1987;111:894-98.

13. Orenstein SR. Oral, pharyngeal, and esophageal motor disorders in infants and children. Gl Motility online [Internet]. 2006 May [cited 2013 May 13];doi:10.1038/gimo38.

14. Dodrill P, McMahon S, Ward E, Weir K, Donovan T, Riddle $B$. Long term sensitivity and feeding skills of low-risk pre-term infants. Early Hum Dev 2004;76:2337.

15. Genna CW. Supporting sucking skills in breastfeeding infants [Internet]. Burlington, Massachusetts: Jones \& Bartlett learning; 2013 [cited on 2014 May 13]. Available from: http://books.google.co.in/books?id= Z9Xw3pkz1YC\&printsec=frontcover\&dq=supporting +breastfeeding+skills\&hl=en\&ei=KVNTcmnKIm3cMv m5PwJ\&sa=X\&oi=book_result\&ct=result\&resnum $=1$ \&ved $=0 \mathrm{CDUQ6AEw} A \# \mathrm{v}=$ onepage \&q\&f=false 